\title{
AOR
}

Selected Papers of \#AolR2018:

The $19^{\text {th }}$ Annual Conference of the

Association of Internet Researchers

Montréal, Canada / 10-13 October 2018

\section{DOING YOUR HOMEWORK: THE USE OF SOCIAL MEDIA AS A FRIENDSHIP FILTER}

\author{
Alecea Standlee \\ Gettysburg College

\section{Introduction}

Today, a proliferation of new communication technologies has reshaped the foundations of social interaction. For young adults who were born in the midst of the current technological age, social media and information distribution technologies and practices are part of normal everyday social interaction, even within their intimate lives. Recent scholarship on the impact of such shifting social practices has identified important patterns in how technologies are utilized as part of social life, and increasingly such scholarship has also identified some of the profound implications of such transformations (Masip, Suau-Martínez, \& Ruiz-Caballero, 2017). Among the most visible and important of these implications is the evidence of the increasing partisan nature of information consumption, sometimes referred to as echo chambers or filter bubbles (Masip, Suau-Martínez, and Ruiz-Caballero 2017; Sunstein 2017). This paper expands this work to consider how the use of social media as a filter in the establishment of friendship networks among college students in offline spaces, shapes the composition of such social networks.

This work is situated within the significant body of social research considering the consequences of techno-mediated cultural integration among the peer groups of young adults. We know that friendships and peer association play a significant role in the development of life long social networks which in turn, shape access to social resources (Su and Chan 2017). Further research suggests that the inter-textual and multi-model structure of communication technology allows for social integration, instant access, centralization, continuous contact and shared imaginaries that foster a sense of group solidarity (Raacke and Bonds-Raacke 2015). However additional work suggests that these technologies and practices make it easier to filter information, allowing individuals to limit their exposure to news and information to like-minded data sources (Pariser 2011; Sunstein 2009, 2017). The consequences of such techno-mediation of social networks are profound. Some scholars have found a degree of social group homogeneity in social media spaces (Seder \& Oishi, 2009), and this may have impacts

Suggested Citation (APA): Standlee,A. (2018, October 10-13 Doing Your Homework: The Use of Social Media As A Friendship Filter. Paper presented at AolR 2018: The $19^{\text {th }}$ Annual Conference of the Association of Internet Researchers. Montréal, Canada: AolR. Retrieved from http://spir.aoir.org. 
on offline relationships as well, as this research shows. Other scholars argue that in fact, these filtering practices may be reshaping core social behaviors (Sunstein 2017), and thus have wide ranging social consequences.

\section{Methodology}

This project focuses on how college students integrate technological communication use into their social lives and considers new patterns of network formation due to the use of such technologies. Research questions of particular interest include:

- What techno-social behaviors are practiced by college students with regard to the establishment and maintenance of friendship networks?

- How do such behavior impact offline social networks, both with regard to establishment and persistence of social networks?

Methodologically, this paper utilizes collected interview data on 52 participants, between the ages of 18 and 24 . The interviews themselves were between about 45 and 90 minutes long and tended to be around one hour on average. In addition, it includes extended ethnographic field work conducted in online social media sites, utilizing the emerging methodological techniques of digital ethnography.

\section{Findings}

The college students who participated in this study rely on complex techno-social communicative processes to establish and maintain interpersonal relationships. Within this cultural environment participants experienced feelings of connection and intimacy, engaged in interactional social processes, conformed and resisted social norms, in short, they participated in genuine social interactions and cultural production. The establishment of a new friendship almost always takes part at least partially on social media, as texting, meeting and hanging out all work together to lead to a friendship. One key aspect of this noted by the participants is the practice of social "background checks" or evaluating potential friends online digital footprint prior to committing even a casual friendship. All but three participants acknowledged the importance of evaluating participants based on social media profiles, before seeking out deeper relationships. The logics behind the need for such research were varied, but "safety," "shared attitudes," and "having something to talk about," were the most commonly cited motivations for participants.

This project allowed for the identification of three key patterns within the qualitative data:

- First, the practice of "doing homework" or conducting social media-based evaluations of social and political positionality shaped decision making about whether or not to pursue and maintain peer friendships among college students in this study.

- Secondly, a narrative of safety and security was central to the behavioral logics expressed by a plurality of research participants, when asked to evaluation their own motivations. Additional logics included social normativity, relationship efficiency and personal enjoyment of the practice. 
- Finally, this behavior is understood by participants to lead to political and social attitude homogeneity within social networks, which is seen as a desirable outcome for a majority of participants.

\section{Conclusions}

Interests and opinions generally bind people closer or pull them apart in face-to-face interactions, yet without technological intervention, the amount of effort that is necessary to identify such similarities or differences results in a median level of social intimacy (Boase and Wellman 2006). Increasingly, ample data is available that suggests that filtering based on shared political and social views is a concern with regard to the distribution of news media and data (Bozdag and Hoven 2015; Flaxman, Goel, and Rao 2016). The consequences of this behavior may include intellectual and behavioral fragmentation.

This project is limited in scope and non-generalizable but suggests an emerging practice among college students that could have significant social and cultural consequences. The technologically enhanced practice of social filtering in offline relationships, has the potential to increase social fragmentation and partisan divides. Other scholars (Sunstein 2009), have elicited the potential social and political consequences of these fragmentation, and this work suggests that interpersonal relationships may also be impacted. The consequences of such fragmentation are becoming increasingly evident in social and political contexts across the globe, with increased radicalization and the decline in social civility in both national and transnational contexts.

\section{References}

Boase, Jeffrey, and Barry Wellman. 2006. "Personal Relationships: On and Off The Internet." In The Cambridge Handbook of Personal Relationships, edited by Anita L. Vangelisti and Daniel Perlman, 1st ed., 914. Cambridge University Press.

Bozdag, Engin, and Jeroen van den Hoven. 2015. "Breaking the Filter Bubble: Democracy and Design." Ethics and Information Technology 17 (4): 249-65. https://doi.org/10.1007/s10676-015-9380-y.

Flaxman, Seth, Sharad Goel, and Justin M. Rao. 2016. "Filter Bubbles, Echo Chambers, and Online News Consumption." Public Opinion Quarterly 80 (S1): 298-320. https://doi.org/10.1093/poq/nfw006.

Masip, Pere, Jaume Suau-Martínez, and Carlos Ruiz-Caballero. 2017. "Questioning the Selective Exposure to News: Understanding the Impact of Social Networks on Political News Consumption." American Behavioral Scientist, May, 0002764217708586. https://doi.org/10.1177/0002764217708586.

Pariser, Eli. 2011. The Filter Bubble: What the Internet Is Hiding From You. Penguin Books Limited. 
Raacke, John, and Jennifer Bonds-Raacke. 2015. "Are Students Really Connected? Predicting College Adjustment from Social Network Usage." Educational Psychology 35 (7): 819-34. https://doi.org/10.1080/01443410.2013.814195.

Su, Chris Chao, and Ngai Keung Chan. 2017. "Predicting Social Capital on Facebook: The Implications of Use Intensity, Perceived Content Desirability, and FacebookEnabled Communication Practices." Computers in Human Behavior 72 (July): 259-68. https://doi.org/10.1016/j.chb.2017.02.058.

Sunstein, Cass R. 2009. Republic.Com 2.0. Princeton, N.J.: Princeton University Press. 2017. \#Republic: Divided Democracy in the Age of Social Media. Princeton: Princeton University Press. 